\title{
Epidemiology of Ductal Carcinoma In Situ
}

Karla Kerlikowske

Correspondence to: Karla Kerlikowske, MD, General Internal Medicine Section, San Francisco Veterans Affairs Medical Center, University of California, San Francisco, 4150 Clement St, 111A1, San Francisco, CA 94121 (e-mail: karla.kerlikowske@ucsf.edu).

Ductal carcinoma in situ (DCIS) is a relatively common diagnosis among women undergoing screening mammography. The greatest increases in DCIS incidence have been in non-comedo subtypes of DCIS that are not associated with subsequent invasive cancer. After a $500 \%$ increase in DCIS from 1983 to 2003, the incidence of DCIS declined in women aged 50 years and older, whereas the incidence in women younger than age 50 continues to increase. Having undergone mammography is one of the strongest and most prevalent risk factors associated with a diagnosis of DCIS. Other risk factors for DCIS are similar to that for invasive cancer including increasing age, family history of breast cancer, high mammographic breast density, and postmenopausal hormone therapy use. Treatment for DCIS is relatively aggressive with the use of both surgery and radiation therapy and most recently adjuvant hormonal therapy. Breast cancer mortality is low and similar with all types of treatment. New information regarding incidence of DCIS and subtypes of DCIS according to frequency of mammography and risk factors could lead to insights into the biology of DCIS.

J Natl Cancer Inst Monogr 2010;41:139-141

The widespread adoption of screening mammography over the past decade has led to an epidemic of diagnoses of ductal carcinoma in situ (DCIS) of the breast. Because it is rarely clinically palpable or symptomatic, DCIS was rarely diagnosed before the advent of modern mammography (1). DCIS now accounts for about $20 \%-$ $25 \%$ of all newly diagnosed cases of breast cancer in the United States and from $17 \%$ to $34 \%$ of mammography-detected cases (24). Approximately one in every 1300 mammography examinations performed will lead to a diagnosis of DCIS, and it is estimated that 62280 cases of DCIS will be diagnosed in $2009(2,5)$.

Data from the Surveillance, Epidemiology, and End Results program depict about a $500 \%$ increase in DCIS among women aged 50 years and older from 1983 to 2003 with incidence of DCIS starting to decline in 2003 (6-8) (Figure 1), possibly because of the decline in use of postmenopausal hormone therapy (9). Among women younger than 50 years, there has been a $290 \%$ increase in DCIS since 1983 and incidence continues to rise (Figure 1) (6). Incidence of non-comedo DCIS, a type of DCIS not associated with subsequent DCIS or invasive cancer, has generally increased across all age groups, whereas rates of comedo DCIS, a type of DCIS associated with subsequent DCIS or invasive cancer, has held constant or decreased (8). Notably, despite 20 years of detecting DCIS on mammography, a decline in invasive cancer in the United States had not been observed until after the recent large decline in postmenopausal hormone therapy (9).

Other than undergoing mammography, older age is one of the strongest risk factors for being diagnosed with DCIS. The rate of DCIS increases with age from 0.6 per 1000 screening examinations in women aged 40-49 years to 1.3 per 1000 screening examinations in women aged 70-84 years $(2,10)$. Population-based incidence and screening rates of DCIS have been found to be similar among white, African American, and Asian/Pacific Islanders $(6,11,12)$. That the rate of DCIS is comparable among women of different ethnicities with a range of invasive cancer rates suggests the incidence of invasive cancer is not directly related to the incidence of DCIS.

Risk factors for DCIS and invasive breast cancer are similar suggesting a common etiology for both diseases. However, in many instances, the association of a given characteristic is more strongly associated with invasive cancer than DCIS. Family history of a first-degree relative with breast cancer, nulliparity or late age at first birth, history of biopsy, late age at menopause, long-term use of postmenopausal estrogen and a progestin therapy, and elevated body mass index in postmenopausal women not taking hormone therapy increase the risk of DCIS and invasive cancer (13-20). High mammographic breast density, one of the strongest risk factors for invasive breast cancer, also has been associated with an increased risk of DCIS $(15,16,21)$. Smoking, lactation, early menarche, increased alcohol consumption, and oral contraceptive use either have not been associated with increased risk of DCIS or results have been conflicting. One study on exercise activity suggests more than 4 hours of exercise may decrease the risk of DCIS, but the results were not conclusive (22). The prevalence of BRCA1 and BRCA2 mutation carriers among women diagnosed with DCIS is similar to that observed in population-based studies of women diagnosed with invasive breast cancer $(23,24)$.

Few studies have examined risk factors for different types of DCIS. Two studies have shown an inverse association with three or more full-term pregnancies and comedo-type DCIS and a positive association with late age at first birth, similar to associations observed with invasive breast cancer, whereas non-comedo type DCIS has not been shown to be associated with reproductive risk factors $(19,25)$. Further research is needed to examine whether genetic and nongenetic risk factors associated with invasive breast cancer are associated differently with various types of DCIS.

A total of $80 \%-85 \%$ of DCIS is detected by mammography and the remaining detected as a lump, and these proportions have been stable over time $(2,3)$. The sensitivity of mammography to detect 


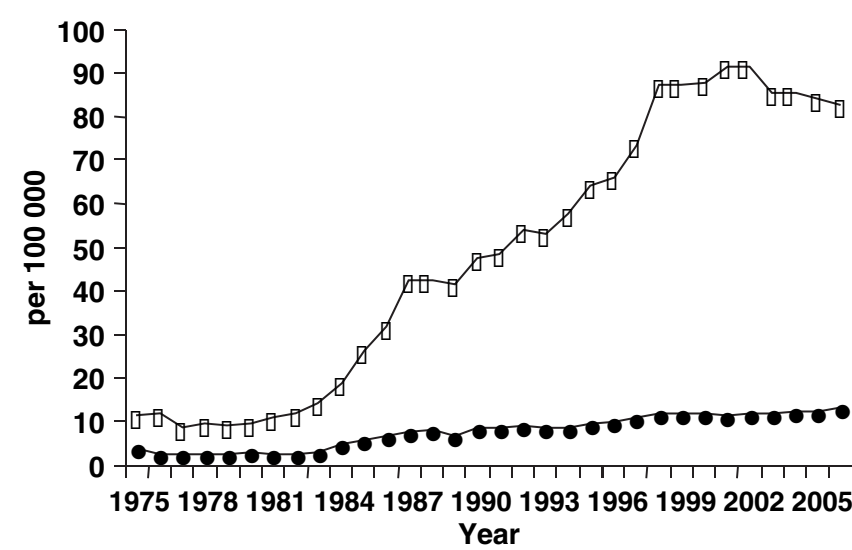

Figure 1. Surveillance, Epidemiology, and End Results program ageadjusted incidence rates of in situ disease of the breast for women aged 50 years and older (line with squares) and younger than 50 years (line with circles) from 1975 to 2006.

DCIS is high at $86 \%$ and varies little with age (2). DCIS usually appears on mammography as linear or multiple clusters of fine granular calcifications with a branching type pattern and can be diagnosed with a core biopsy or needle localization excisional biopsy. About $96 \%$ of DCIS lesions diagnosed on mammography are detected by performing a biopsy of calcifications (26).

Given that the natural history of DCIS is unknown, in particular, the natural history of mammographically detected DCIS, the clinical dilemma lies in not being able to distinguish which lesions will be associated with a subsequent invasive cancer. This results in the vast majority of women with DCIS receiving some surgical treatment. Almost all women who have DCIS detected are currently treated either by mastectomy or by lumpectomy with or without radiation, and with or without adjuvant hormonal therapy with less than $3 \%$ receiving no treatment (27). The proportion of women undergoing mastectomy for DCIS has declined over time, but the absolute numbers of women having mastectomy to treat DCIS have remained the same because of the rising incidence of DCIS (28). The proportion of women undergoing lumpectomy alone has remained constant over time, whereas there has been an increase in the proportion of women receiving lumpectomy and radiation for treatment of DCIS. Axillary lymph node dissection has declined from 34\% of cases undergoing dissection in 1992 to $11 \%$ in $2002(27,28)$. Approximately $13 \%-19 \%$ of women who undergo lumpectomy are receiving adjuvant hormonal therapy $(29,30)$. An increasing rate of contralateral prophylactic mastectomy from $6.4 \%$ in 1998 to $18.4 \%$ in 2005 has been reported among women who underwent mastectomy to treat DCIS (31). Although one might conclude that the aggressiveness of treatment has decreased as a result of the decreased proportion of women undergoing mastectomy and lymph node dissection, the opposite can also be said with the increasing use of adjuvant radiation and hormonal therapy and contralateral prophylactic mastectomy.

Mortality from breast cancer is low among women diagnosed with DCIS regardless of the type of treatment women undergo. Only $1.0 \%-2.6 \%$ of women diagnosed with DCIS will die of invasive breast cancer within $8-10$ years of diagnosis (32-34). Whether the low risk of death from breast cancer is because of very effective treatments or the fact that the majority of DCIS are relatively benign, or both are unclear. There are no data that demonstrate detection of DCIS by mammography averts breast cancer deaths. Thus, screening mammography may be benefiting some women whose DCIS would be associated with subsequent invasive cancer, whereas it is potentially harming other women whose DCIS would never be associated with subsequent invasive cancer, who for lack of good prognostic indicators, are almost always treated with surgery and adjuvant therapies.

In summary, DCIS is relatively common diagnosis among women undergoing mammography. Risk factors for development of DCIS are similar to those of invasive cancer. Overall, the incidence of DCIS has been stable in the last 5 years, with incidence declining in women aged 50-69 years with the decline in use of postmenopausal hormone therapy. The incidence of DCIS subtypes associated with subsequent invasive cancer has been stable including those detected by palpation and comedo-type DCIS. Treatment for DCIS is relatively aggressive with use of both surgery and radiation therapy and most recently adjuvant hormonal therapy. New information regarding incidence of DCIS and subtypes of DCIS according to frequency of mammography and risk factors could lead to insights into the biology of DCIS.

\section{References}

1. White E, Lee CY, Kristal AR. Evaluation of the increase in breast cancer incidence in relation to mammography use. 7 Natl Cancer Inst. 1990;82(19): $1546-1552$.

2. Ernster V, Ballard-Barbash R, Barlow W, et al. Detection of DCIS in women undergoing screening mammography. 7 Natl Cancer Inst. 2002; 94(20):1546-1554.

3. Kerlikowske K, Grady D, Barclay J, Sickles EA, Eaton A, Ernster V. Positive predictive value of screening mammography by age and family history of breast cancer. FAMA. 1993;270(20):2444-2450.

4. May D, Lee N, Richardson L, Giustozzi A, Bobo J. Mammography and breast cancer detection by race and Hispanic ethnicity: results from a national program (United States). Cancer Causes Control. 2000;11(8): 697-705.

5. Jemal A, Siegel R, Ward E, Hao Y, Xu J, Thun M. Cancer statistics, 2009. CA Cancer J Clin. 2009;59(4):225-249.

6. Horner M, Ries L, Krapcho M, et al. SEER Cancer Statistics Review, 1975-2006. Bethesda, MD: National Cancer Institute; 2009. http://seer.cancer .gov/csr/1975_2006/, based on November 2008 SEER data submission, posted to the SEER Web site, September 1, 2009. Accessed August 30, 2010.

7. Ernster VL, Barclay J, Kerlikowske K, Grady D, Henderson IC. Incidence of and treatment for ductal carcinoma in situ of the breast. $7 A M A$. 1996;275(12):913-918.

8. Li C, Daling J, Malone K. Age-specific incidence rates of in situ breast carcinomas by histologic type, 1980 to 2001. Cancer Epidemiol Biomarkers Prev. 2005;14(4):1008-1011.

9. Kerlikowske K, Miglioretti D, Buist D, Walker R, Carney P. Declines in invasive breast cancer and use of postmenopausal hormone therapy in a screening mammography population. 7 Natl Cancer Inst. 2007;99(17): $1335-1339$.

10. Randolph W, Goodwin J, Mahnken J, Freeman J. Regular mammography use is associated with elimination of age-related disparities in size and stage of breast cancer at diagnosis. Ann Intern Med. 2002;137(10): 783-790.

11. Ghafoor A, Jemal A, Ward E, Cokkinides V, Smith R, Thun M. Trends in breast cancer by race and ethnicity. CA Cancer 7 Clin. 2003;53(6):342-355.

12. Kerlikowske K, Creasman J, Leung J, Smith-Bindman R, Ernster V. Differences in screening mammography outcomes among white and Asian women. Arch Intern Med. 2005;165(16):1862-1868. 
13. Claus E, Stowe $M$, Carter D. Breast carcinoma in situ: risk factors and screening patterns. 7 Natl Cancer Inst. 2001;93(23):1811-1817.

14. Kerlikowske K, Barclay J, Grady D, Sickles E, Ernster V. Comparison of risk factors for ductal carcinoma in situ and invasive breast cancer. 7 Natl Cancer Inst. 1997;89(1):77-82.

15. Reinier K, Vacek P, Geller B. Risk factors for breast carcinoma in situ versus invasive breast cancer in a prospective study of pre- and postmenopausal women. Breast Cancer Res Treat. 2007;103(3):343-348.

16. Gill JK, Maskarinec G, Pagano I, Kolonel LN. The association of mammographic density with ductal carcinoma in situ of the breast: the Multiethnic Cohort. Breast Cancer Res. 2006;8(3):R30.

17. Trentham-Dietz A, Newcomb P, Storer B, Remington P. Risk factors for carcinoma in situ of the breast. Cancer Epidemiol Biomarkers Prev. 2000;9(7):697-703.

18. Kerlikowske K, Walker R, Miglioretti D, Desai A, Ballard-Barbash R, Buist D. Obesity, mammography use and accuracy, and advanced breast cancer risk. 7 Natl Cancer Inst. 2008;100(23):1724-1733.

19. Wohlfahrt J, Rank F, Kroman N, Melbye M. A comparison of reproductive risk factors for CIS lesions and invasive breast cancer. Int 7 Cancer. 2004;108(5):750-753.

20. Kerlikowske K, Miglioretti D, Ballard-Barbash R, et al. Prognostic characteristics of breast cancer among postmenopausal hormone users in a screened population. 7 Clin Oncol. 2003;21(23):4314-4321.

21. MacKenzie T, Titus-Ernstoff L, Vacek P, et al. Breast density in relation to risk of ductal carcinoma in situ of the breast in women undergoing screening mammography. Cancer Causes Control. 2007;18(9):939-945.

22. Patel AV, Press MF, Meeske K, Calle EE, Bernstein L. Lifetime recreational exercise activity and risk of breast carcinoma in situ. Cancer. 2003; 98(10):2161-2169.

23. Claus E, Petruzella S, Matloff E, Carter D. Prevalence of BRCA1 and BRCA2 mutations in women diagnosed with ductal carcinoma in situ. 7АMA. 2005;294(8):964-969.

24. Syrjakoski K, Vahteristo P, Eerola H, et al. Population-based study of BRCA1 and BRCA2 mutations in 1035 unselected Finnish breast cancer patients. $\mathcal{F}$ Natl Cancer Inst. 2000;92(18):1529-1531.

25. Phillips LS, Millikan RC, Schroeder JC, Barnholtz-Sloan JS, Levine BJ. Reproductive and hormonal risk factors for ductal carcinoma in situ of the breast. Cancer Epidemiol Biomarkers Prev. 2009;18(5):1507-1514.
26. Venkatesan A, Chu P, Kerlikowske K, Sickles E, Smith-Bindman R. Positive predictive value of specific mammographic findings according to reader and patient variables. Radiology. 2009;250(3):648-657.

27. Baxter NN, Virnig BA, Durham SB, Tuttle TM. Trends in the treatment of ductal carcinoma in situ of the breast. 7 Natl Cancer Inst. 2004;96(6): 443-448.

28. Kumar AS, Bhatia V, Henderson IC. Overdiagnosis and overtreatment of breast cancer: rates of ductal carcinoma in situ: a US perspective. Breast Cancer Res. 2005;7(6):271-275.

29. Jackson LC, Camacho F, Levine EA, Anderson RT, Stewart JHIV. Patterns of care analysis among women with ductal carcinoma in situ in North Carolina. Am 7 Surg. 2008;195(2):164-169.

30. Sumner WE, Koniaris LG, Snell SE, et al. Results of 23,810 cases of ductal carcinoma-in-situ. Ann Surg Oncol. 2007;14(5):1638-1643.

31. Tuttle TJ, Habermann EB, Arrington A, Abraham A, Morris TJ, Virnig BA. Increasing rates of contralateral prophylactic mastectomy among patients with ductal carcinoma in situ. F Clin Oncol. 2009;27(9):1362-1367.

32. Ernster VL, Barclay J, Kerlikowske K, Wilkie H, Barbash R. Mortality among women with ductal carcinoma in situ of the breast in the population-based SEER Program. Arch Intern Med. 2000;160(7):953-958.

33. Fisher B, Dignam J, Wolmark N, et al. Lumpectomy and radiation therapy for the treatment of intraductal breast cancer: findings from national surgical adjuvant breast and bowel project B-17. 7 Clin Oncol. 1998;169(2): $441-452$.

34. Kerlikowske K, Molinaro A, Cha I, et al. Characteristics associated with recurrence among women with ductal carcinoma in situ treated by lumpectomy. 7 Natl Cancer Inst. 2003;95(22):1692-1702.

\section{Funding}

NCI-funded UCSF Breast Cancer SPORE (P50 CA58207).

Affiliations of author: General Internal Medicine Section, Department of Veterans Affairs; Department of Medicine and Helen Diller Family Comprehensive Cancer Center, University of California, San Francisco, San Francisco, CA. 